\title{
Sciendo
}

DOI: $10.1515 /$ sspjce-2019-0002

\section{Light Pipe Comparative Study}

\author{
Ayodeji Omishore, Petr Mohelník, Denis Míček \\ Brno University of Technology, Czech Republic \\ Faculty of Civil Engineering, Institute of Building Structures \\ e-mail: ayodejiomi@gmail.com, mohelnik.p@fce.vutbr.cz,denis.micek@gmail.com
}

\begin{abstract}
Results of daylight illuminance measurements of the field testing of two light guides with different roof installations is presented in the article. The first one is a common tubular system with a glass roof dome and the second one is a new light guide prototype with a concentrator head. The daylight illuminance was measured in a test chamber with the light guides installation. The measurements were carried out at the end of a summer season from August to September 2017. The measured data show differences in the daylight illuminance of the two tested light guides. The measured data were compared with simulation outputs in software Holigilm. In summary, it was found that the common light guide is about 37 percentage more efficient in light transmittance compared to the new light guide prototype. In temperate climate with dominant cloudy and partly cloudy daylight conditions the common light guide transmitted more light that the device with the concentrator head which reduced light transmission much more.
\end{abstract}

Key words: light guide, light measurements, daylight evaluations

\section{Introduction}

Light guide are tubular devices that transmit daylight into internal parts of buildings. They are usually installed in roofs constructions [1]. Common light guides consist of roof domes, tubes with mirrored surface and diffusers. Daylight is transmitted through the roof dome into the tube and it is scattered in the interior due to the diffuser [2,3]. Optical properties of light guide components and their installation are key factors influencing the light guide efficiency $[3,4]$. Most research projects have been focused on the solution of light guiding systems recently. Evaluations and studies of light guides were mostly focused on the influence of tubes and their dimensions as well as reflectance on the daylighting inside of building interiors [6-11]. Theoretical studies were pointed on the light transmittance of tubes with high reflective surfaces [12,13]. Analytic descriptions, physical models as well as algorithms and computer simulations of various types of light pipes were published [14,15]. A physical model for interior illuminance calculation applied to cylindrical guiding systems was developed [16]. Ray-tracing models [17-19] were used for developing of the light guide models and progressive photon mapping and stochastic progressive photon mapping were tested [20]. The 
simulations were used for the modelling of the real building and light guide design [21-24]. Achieved and predicted installation performances were studies [25] and good design practices of the light guides installations were published [26,27].

Light reflectance of the light guides influences light transmittance through the light guiding systems. Installations of roof transparent covers play also important role in the light guiding design and their applications. Transparent covers at the top of light guides in roof installations are usually completed by domes or collector heads. Domes are made of glass or transparent plastics like PMMA. Collector heads have glass cover over a system consisting of mirrors and/or parabolic concentrators focusing light rays into the light tube [28,29]. The light focusing elements and reflecting parabolic head are used for enhancement of the light guiding systems efficiency. Efficiency of the light guiding systems is important for both the indoor visual comfort and energy savings [30-32].

Applications of the light focusing and redirecting reflective elements for light guides should be considered in the context of the light guide geometry and its installation in the building constructions. Otherwise the very efficient light guide system but installed in less favourable position in the roof could decrease its efficiency as it is presented in the article. The article demonstrates main results of field testing of two light guides with different roof installations. Presented study is focused on the light guide transmittance has been involved into the university research project orientated on research of advanced materials, structures and technologies.

A comparative study was carried out for two light guides with different roof dome installations. The study was carried out for the testing of the new light guide prototype and potentials its applications compared to the common light guide systems in temperate climatic conditions. The light guide prototype has a special light concentrator head. The head consists of two parabolic mirrors which concentrate and redirect sunlight into the tube. The prototype is compared with the commercially available light guide with transparent roof dome without any concentrator mirrors. The comparative study was completed in the field test chamber under real sky conditions. The purpose of the testing is to find advantages and possible drawbacks of the prototype light guiding system and suggest some improvements for its applications in buildings.
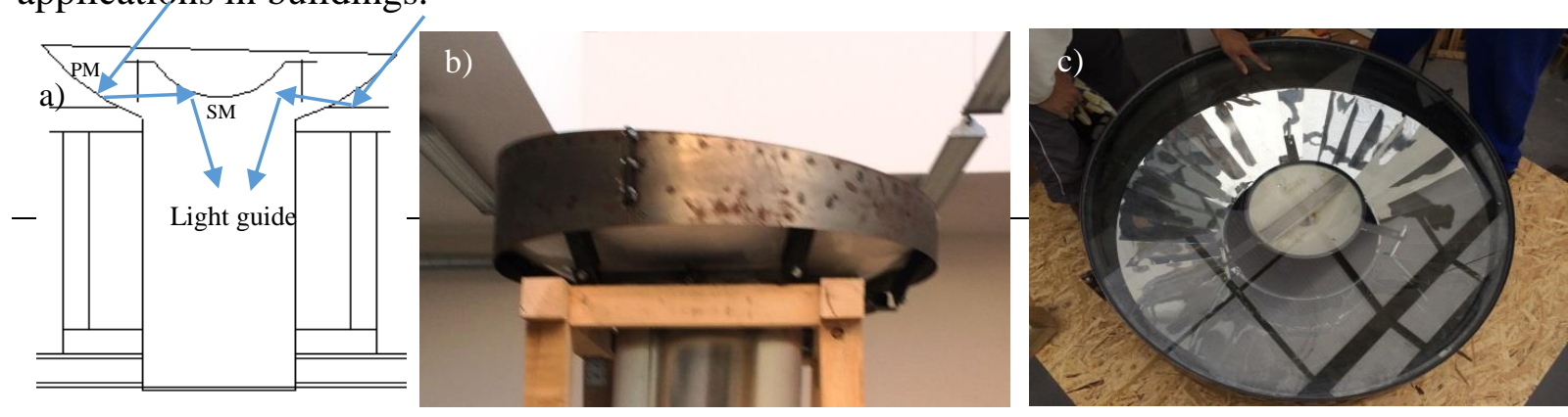

Figure 1: Concentrator head of the light guide prototype

a) schematic section of the light guide with the concentrator head (PM-primary mirror, SM-secondary mirror), b) side view, c) view into the parabolic concentrator. 


\section{Method}

Two light guides with identical tubes of length $0.6 \mathrm{~m}$ and diameter $0.52 \mathrm{~m}$ were installed into a roof of a test chamber, Figure 2. Light guides have different roof domes - the first one has a mirror parabolic head with a flat glass cover (light guide LP1) and the second one is with a glass cupola (light guide LP2), Figure 1 and Figure 2. Both of the light guides were equipped by internal transparent plastic cover - diffuser. The diffusers scattered light into the chamber. The chamber internal room is separated by curtain into two identical parts. Each light guide is installed over its own part. Daylight illuminance chambers was monitored simultaneously. Internal surfaces of the chamber were faced with black cloth. It means that only sky component of daylight transmitted through the light guide influences indoor illuminance levels. External horizontal illuminance on roof of the test chamber was also monitored. A set of calibrated illuminance meters Lutron LX-1128SD were used for the experiment. Achieved measured illuminance were completed in one-minute monitoring intervals for one month period between $22^{\text {nd }}$ August and $23^{\text {rd }}$ September 2017. The monitoring time period is characteristic with number of days with clear sky conditions and higher external illuminance levels of the end of the summer period. These conditions are more convenient for the intended comparative study. Illuminance meters were positioned in the axes of the light guide and in the distance $2.8 \mathrm{~m}$ from the light guide diffuser. The testing was completed in the temperate climatic region of city Brno in the Czech Republic, latitude $49^{\circ} 12^{\prime}$, longitude $16^{\circ} 37^{\prime}$, altitude $237 \mathrm{~m}$.
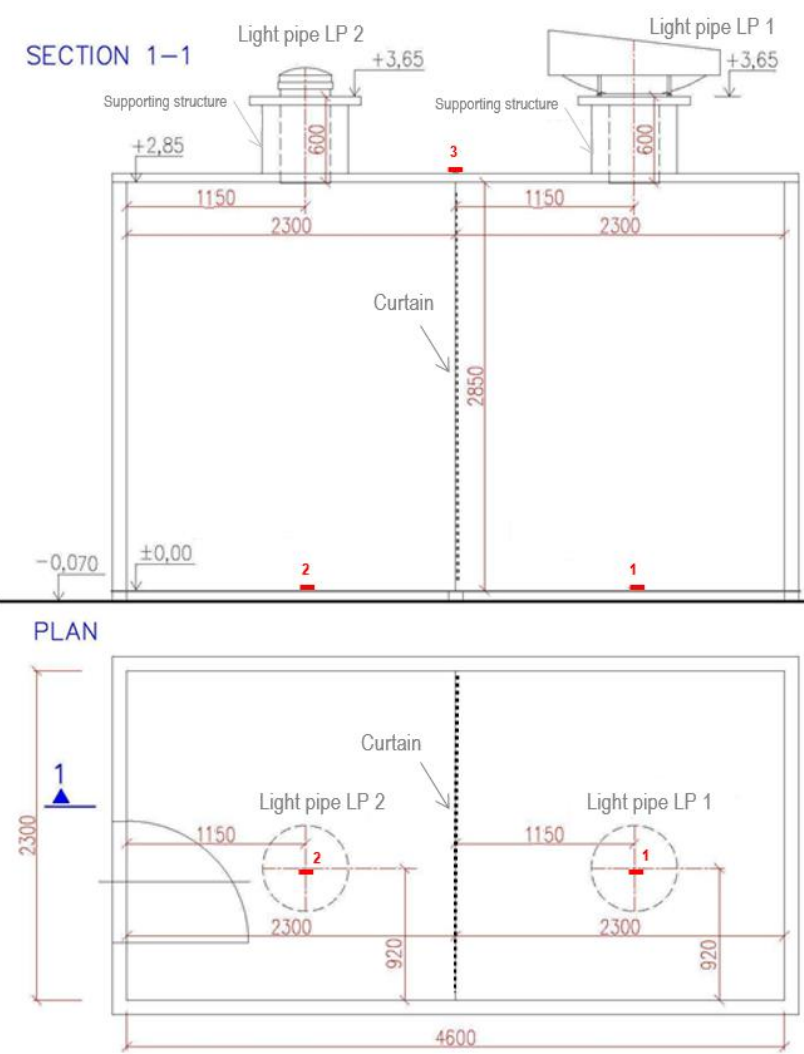

Figure 2: Scheme of installation of light guides LP1 and LP2

1 (resp. 2)-illuminance meters for LP1 (resp. LP2) light measurements,

3 - illuminance meter for external horizontal illuminance measurement a)

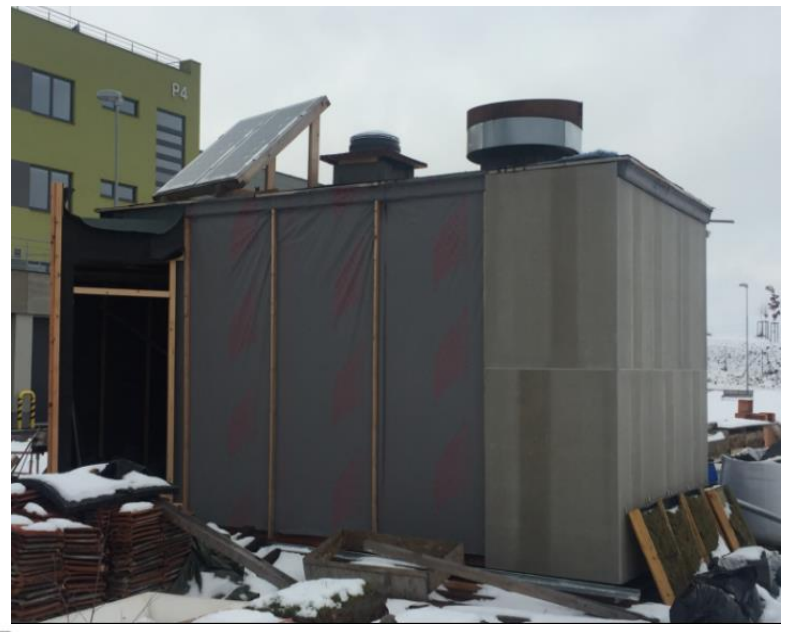

b)
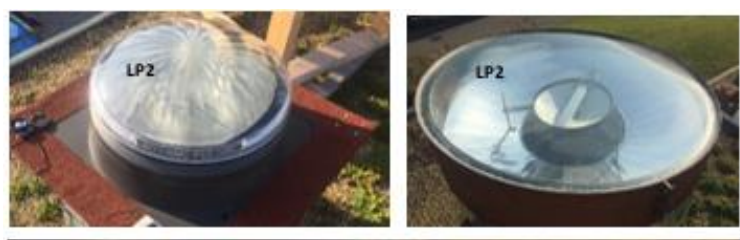

c)

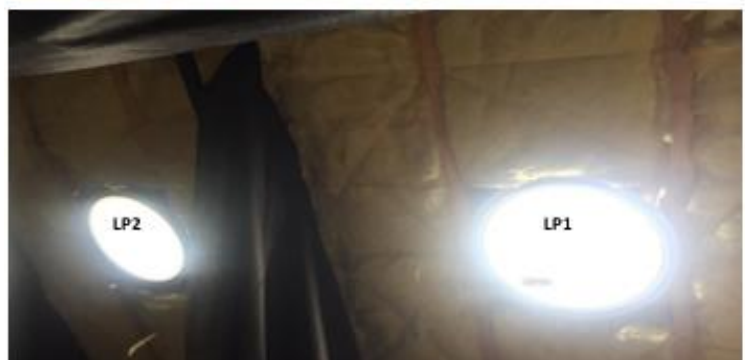

Fig. 3 Photographs of light guides LP1 and LP2 installation

a) the test chamber

b) light concentrator heat of LP1 and roof dome of LP2

c) view from the test chamber to the diffusors of LP1 and LP2 
The light measurements were completed between August and September 2017. The illuminance measurement results give overview about the light transmittance of the tested light guides. Examples of the illuminance under LP1 and LP2 compared to the simultaneously measured external horizontal illuminance are shown in Figure 4. It is obvious that the illuminance under LP2 is higher compared to the daylight level under the LP1. This can be noticed in daily illuminance profiles of characteristic days shown in Figures 5 a 6 . Measurements for partly cloudy sky gives more correlated data (Fig. 5) compared to the illuminance under sky with dynamic illuminance variations (Fig. 6). Values of mean, median, maximum and minimum values over the monitored period are summarized in Figure 7. In summary, the percentage of the difference of mean illuminance values from the illuminance measurements under LP1 and LP2 is shown in the graph of Figure 8. Results from the presented measurements gives information that the LP1 transmitted all the time more daylight compared to the LP2. On an average, the light transmittance is reduced about 37 percent as shown in Figure 8. It means that the concentrator head of the LP1 prototype is obstructive for daylighting during partly cloudy and cloudy sky conditions.

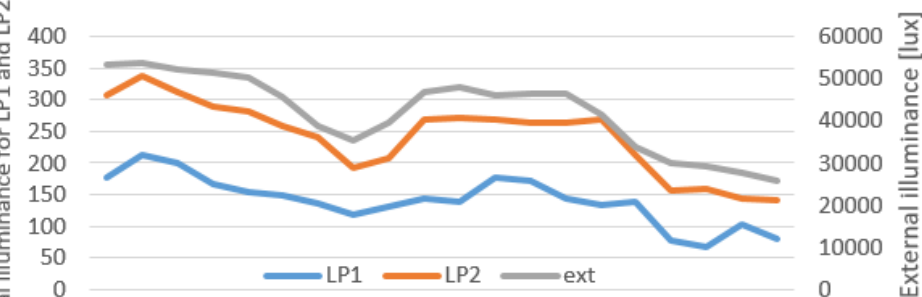

\begin{tabular}{|c|c|c|c|}
\hline & \multicolumn{3}{|c|}{ Illuminance [lux } \\
\hline plem & LP1 & LP2 & External \\
\hline mean & 141 & 242 & 42115 \\
\hline medic & 141 & 264 & 45850 \\
\hline $\max$ & 213 & 338 & 53600 \\
\hline $\min$ & 68 & 141 & 25800 \\
\hline
\end{tabular}

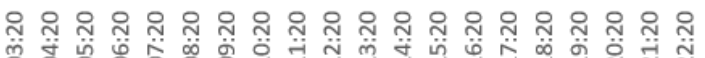

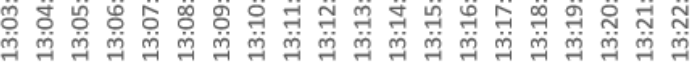

Time

04/09/2017

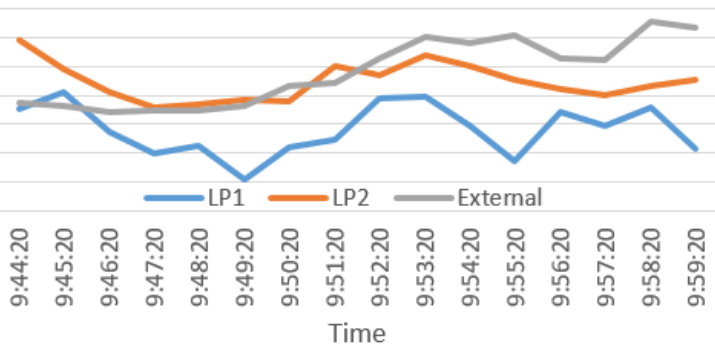

\begin{tabular}{|c|c|c|c|}
\hline & \multicolumn{3}{|c|}{ Illuminance [lux] } \\
\hline September & LP1 & LP2 & Extern \\
\hline mean & 56 & 89 & 791 \\
\hline median & 56 & 88 & 4825 \\
\hline $\max$ & 82 & 118 & 6550 \\
\hline $\min$ & 21 & 72 & 3390 \\
\hline
\end{tabular}

$11 / 09 / 2017$

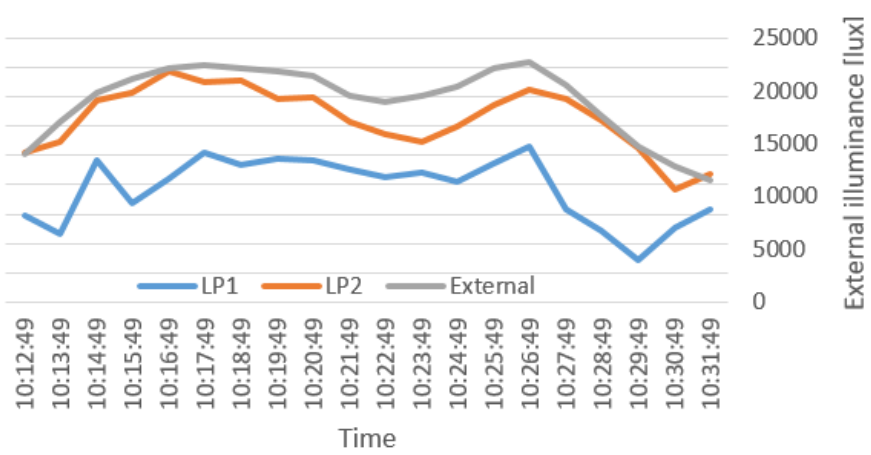

\begin{tabular}{cccc} 
& \multicolumn{3}{c}{ Illuminance [lux] } \\
$11^{\text {th }}$ & LP1 & LP2 & External \\
September & & \\
mean & 77 & 125 & 19134 \\
median & 84 & 129 & 20085 \\
$\max$ & 106 & 158 & 22800 \\
$\min$ & 29 & 77 & 11500
\end{tabular}

Figure 4: Examples of the internal and external horizontal illuminance profiles 
$01 / 09 / 2017$

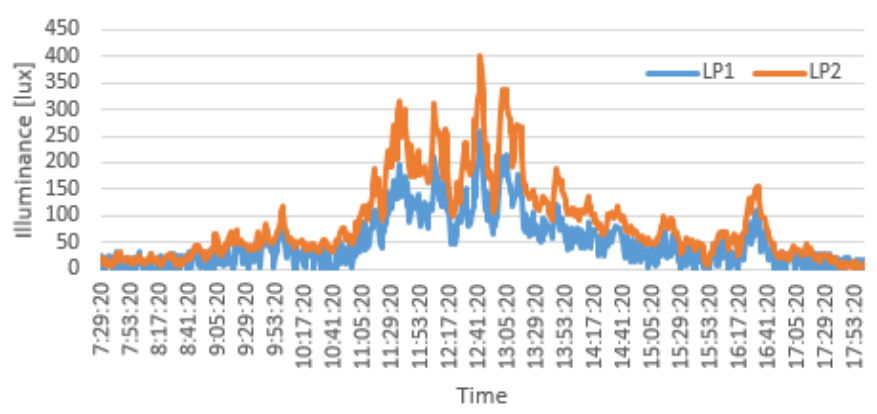

$02 / 09 / 2017$

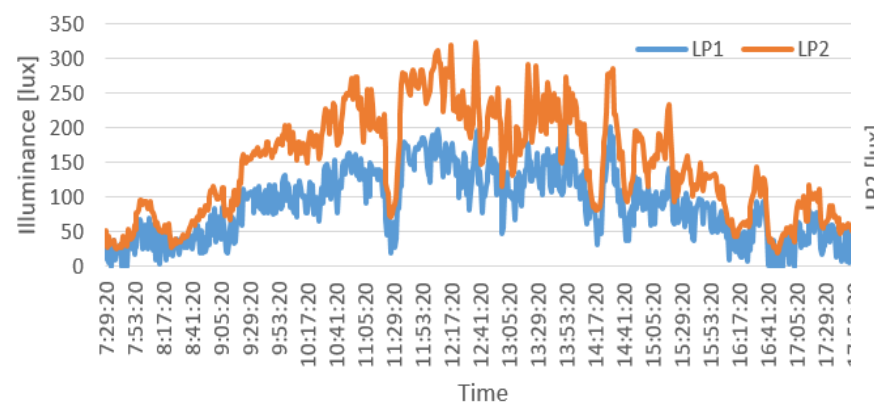

$01 / 09 / 2017$
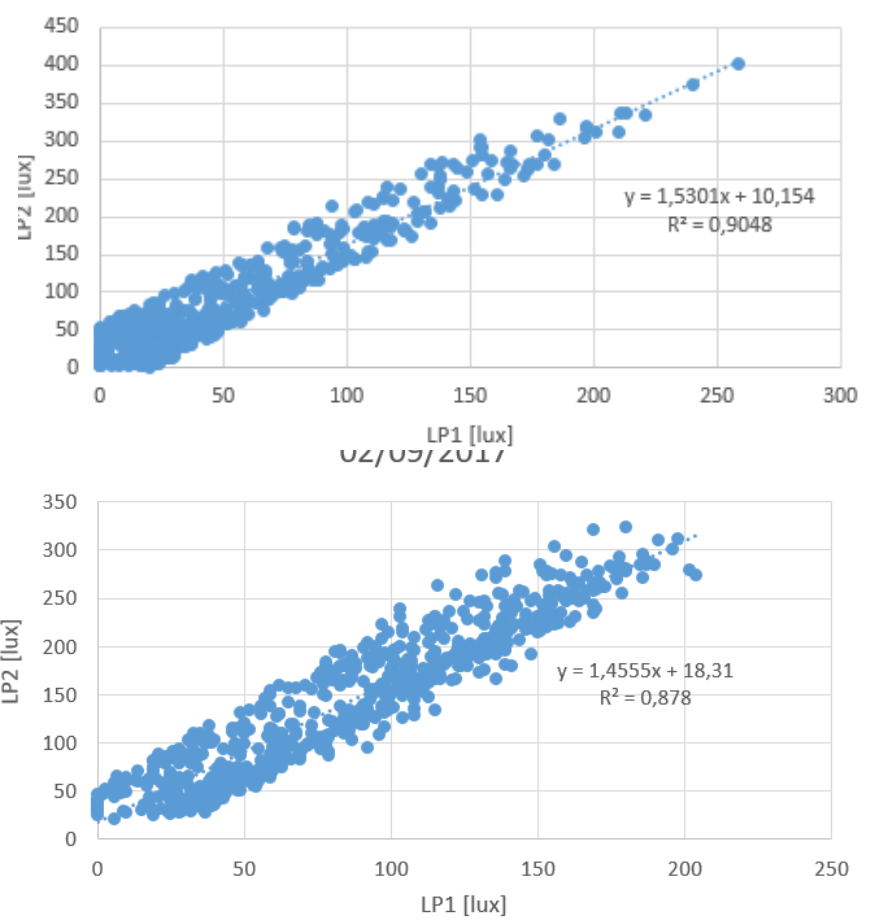

Figure 5: Daily illuminance profiles and correlation graphs for illuminances of LP1 and LP2 (partly cloudy sky conditions, on the $1^{\text {st }}$ September and $2^{\text {nd }}$ September 2017)

$16 / 09 / 2017$
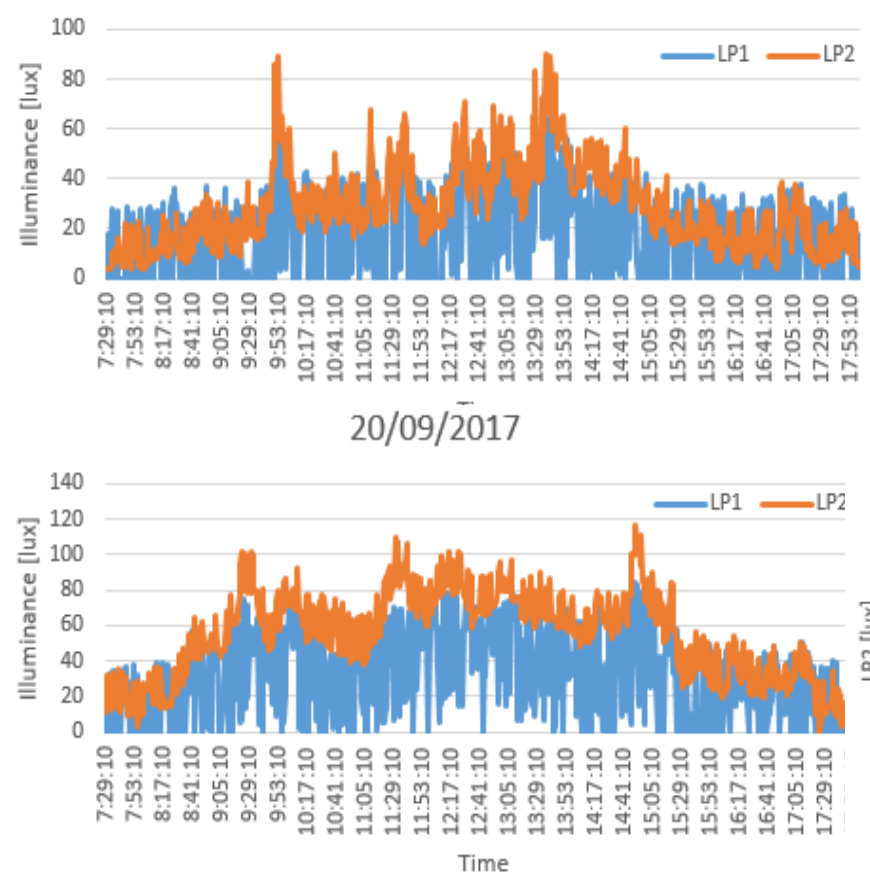

$16 / 09 / 2017$
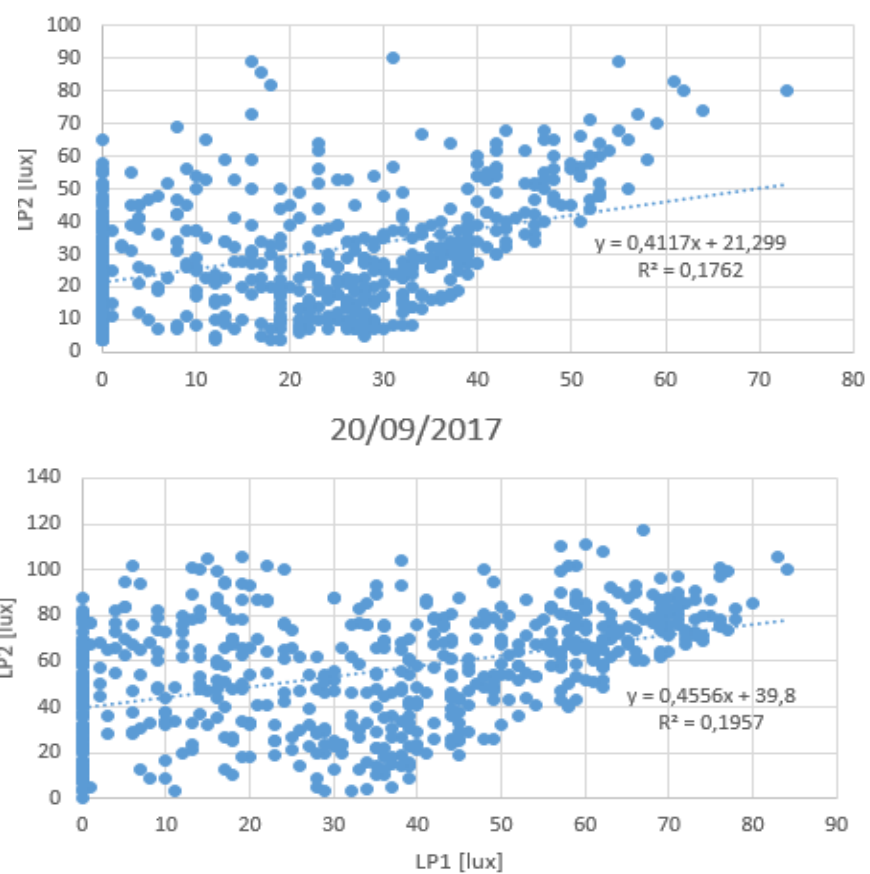

Figure 6: Daily illuminance profiles and correlation graphs for illuminances of LP1 and LP2 (dynamic changes of cloudy sky, on the $16^{\text {th }}$ September and $20^{\text {th }}$ September 2017) 


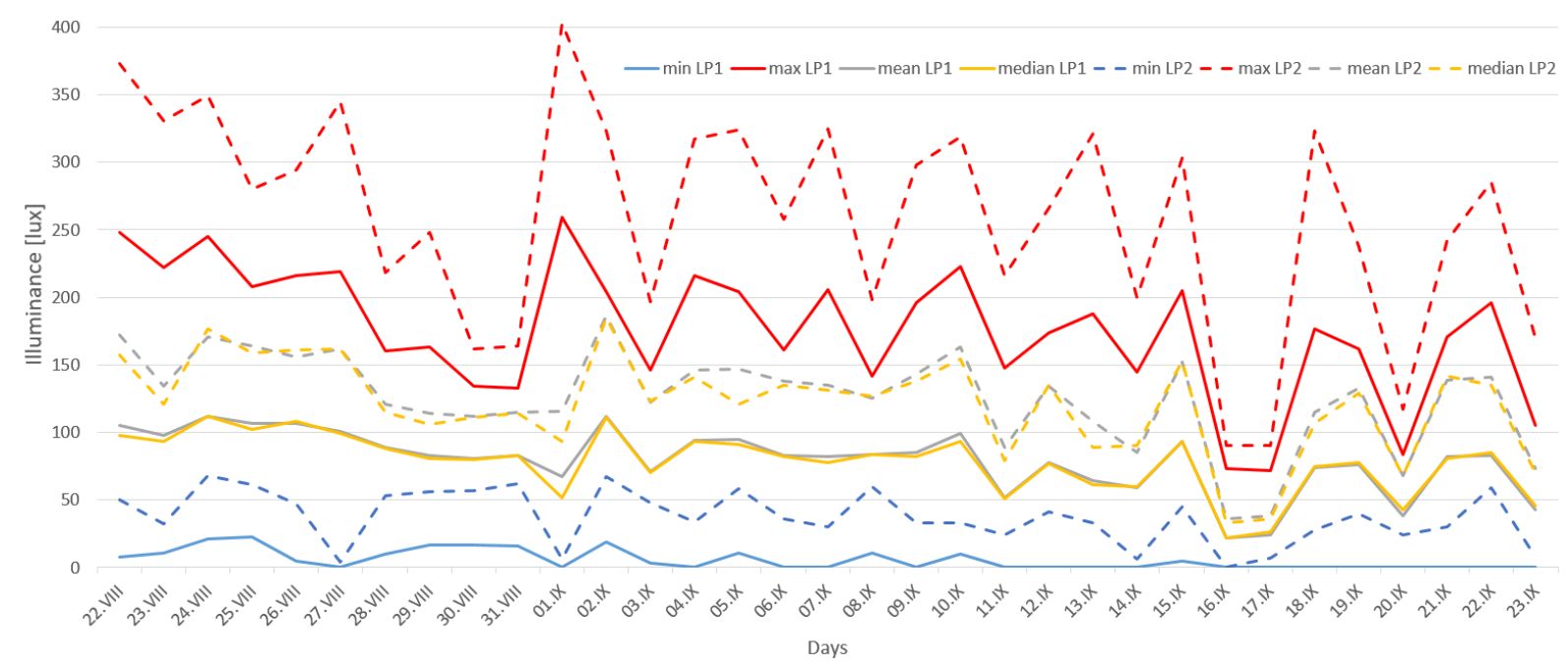

Figure 7: Daily illuminance min, max, mean and median values (from 22/08 to 23/09/2017)

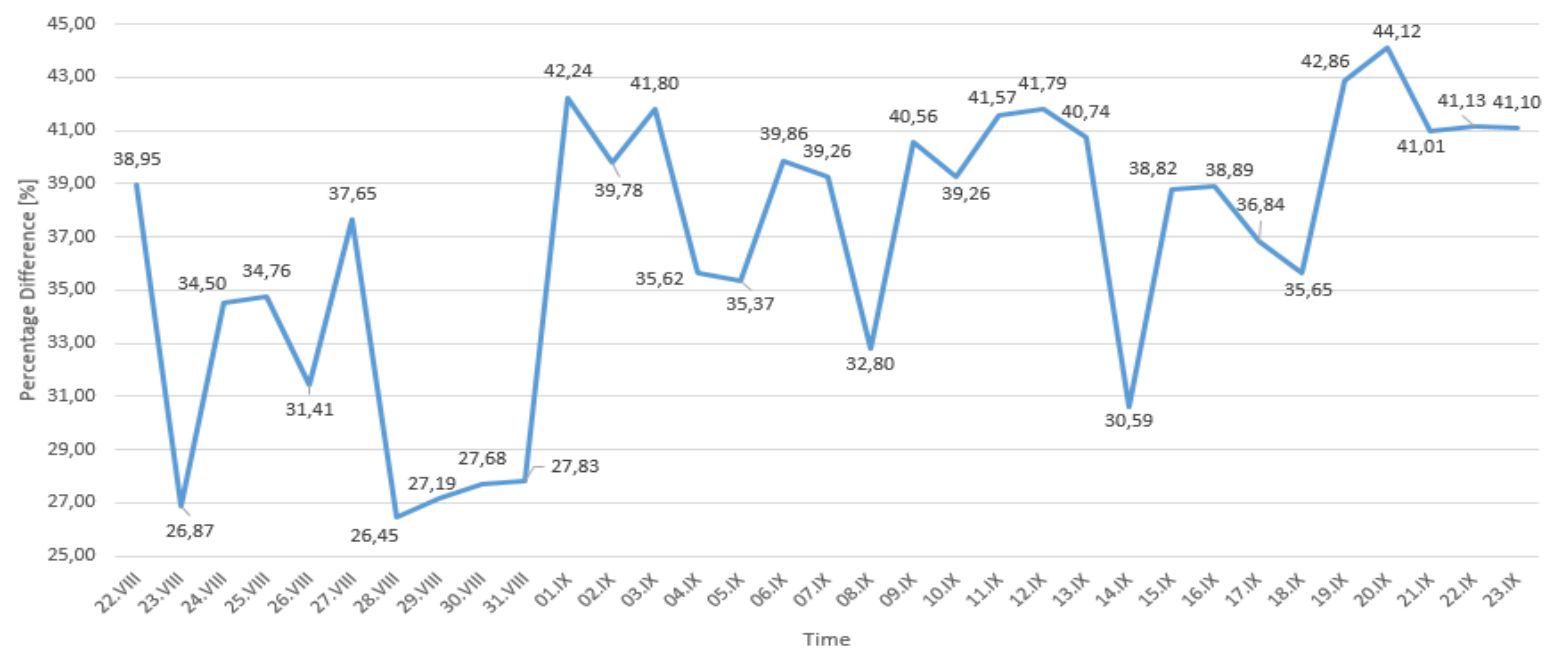

Figure 8: Percentage of the difference between mean values of LP1 and LP2 illuminance

\section{Daylight simulations}

Daylight simulations of the tested light guides LP1 and LP2 were run in software Holigilm [16]. Simulations were carried out for the 1st September, overcast sky [33] to be compared with data from measurements at daytime 12:00. Parameters selected for the simulations are:

1) dimensions of light types LP1 and LP2 are: length $0.6 \mathrm{~m}$, diameter $0.52 \mathrm{~m}$,

2) light reflectance of internal surface of the both tubes is $\rho=0.97$.

3) light transmittance of ceiling diffusers of LP1 and LP2 is $\tau=0.75$.

4) light transmittance $\tau[-]$ of roof transparent covers of LP1 and LP2 are:

- parabolic concentrator head of LP1: $\tau 1=0.53$, - roof cupola of LP2: $\tau 2=0.9$.

The light transmittance of the LP1 concentrator head was determined from light transmittance of glass dome 0.9 decreased for the reduction determined from the illuminance measurements in the test chamber which is in average 37 percentage. The simulation outputs of internal horizontal illuminance at level $2.8 \mathrm{~m}$ under the ceiling diffusers (the test chamber floor level) were evaluated. Positions of the light guides LP1 and LP2 are in accordance with Figure 2, it means $\mathrm{x}=0.92 \mathrm{~m}, \mathrm{y}=1.15, \mathrm{z}=2.8 \mathrm{~m}$ for coordinate system with 0.0 in the left hand side lower corner of the schemes in Figure 9. 
SSP - JOURNAL OF CIVIL ENGINEERING Vol. 14, Issue 1, 2019

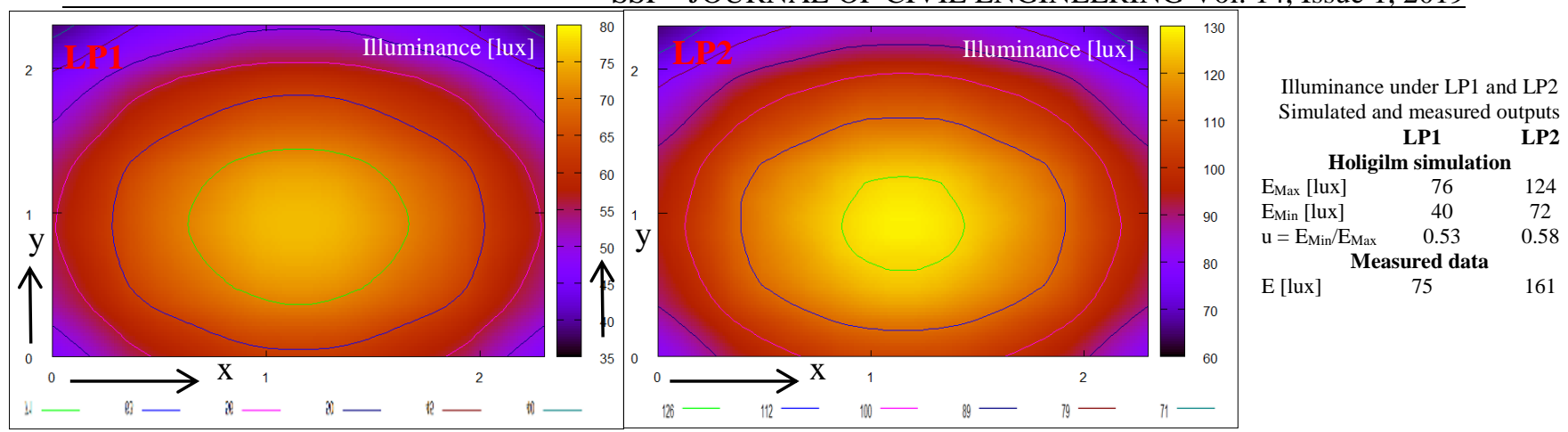

Figure 9: Illuminance E [lux] under light pipes LP1 and LP2, on 1st September, 12:00

Simulation output are in conformity with the measured data. The illuminance simulations also confirm that in this case the light guide LP1 with the concentrator head is less efficient system that gives lower illuminance level on the working plane indoors compared to light guide LP2. The concentrator head in static horizontal position represents an obstruction for daylight transmittance. Especially for overcast and partly cloudy sky conditions the system with the concentrator head in static position is less efficient. Also the secondary concave mirror of the head appears to be less convenient than the convex one. If light rays affect the concentrator head at low solar altitude they are reflected outside of the focus mirror. Then light transport is due to multi-reflections inside of the light tube and the effect of the concentrator head is not fully used. It is recommended to complete the concentrator head with a sun tracking system for activation of the head direction towards the solar radiation in case of the clear sky. Example of the light reflection and redirection on the parabolic head on the 1st September at 9:00 and 12:00 is shown in Figure 10 in parabolic head position $0^{\circ}$ (horizontal), $25^{\circ}$ a between $40^{\circ}-55^{\circ}$. Dependence of the rotation on the solar altitude is shown in Figure 11.

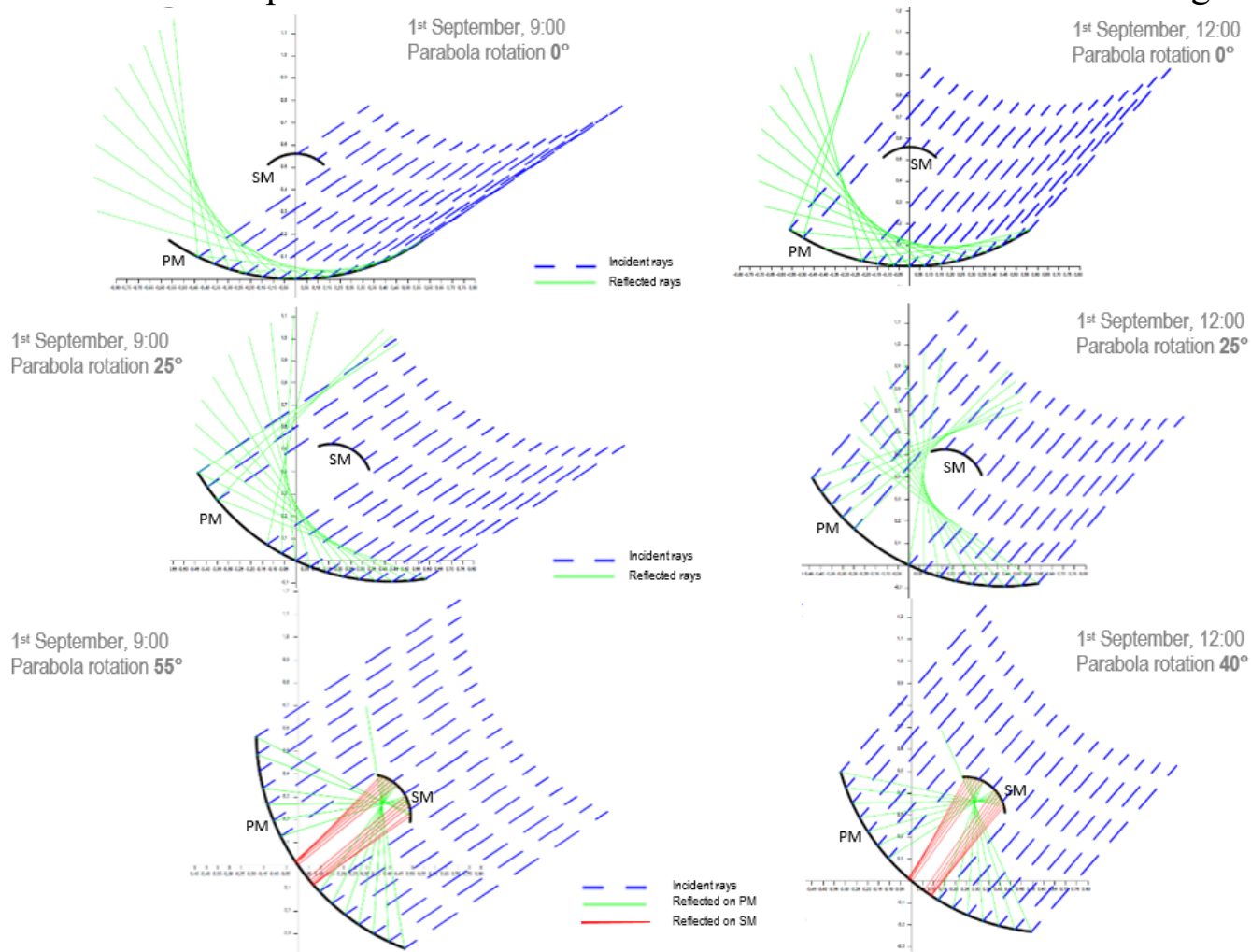

Figure 10: Examples of the light reflection and redirection on the parabolic head PM-primary mirror, SM-secondary mirror 


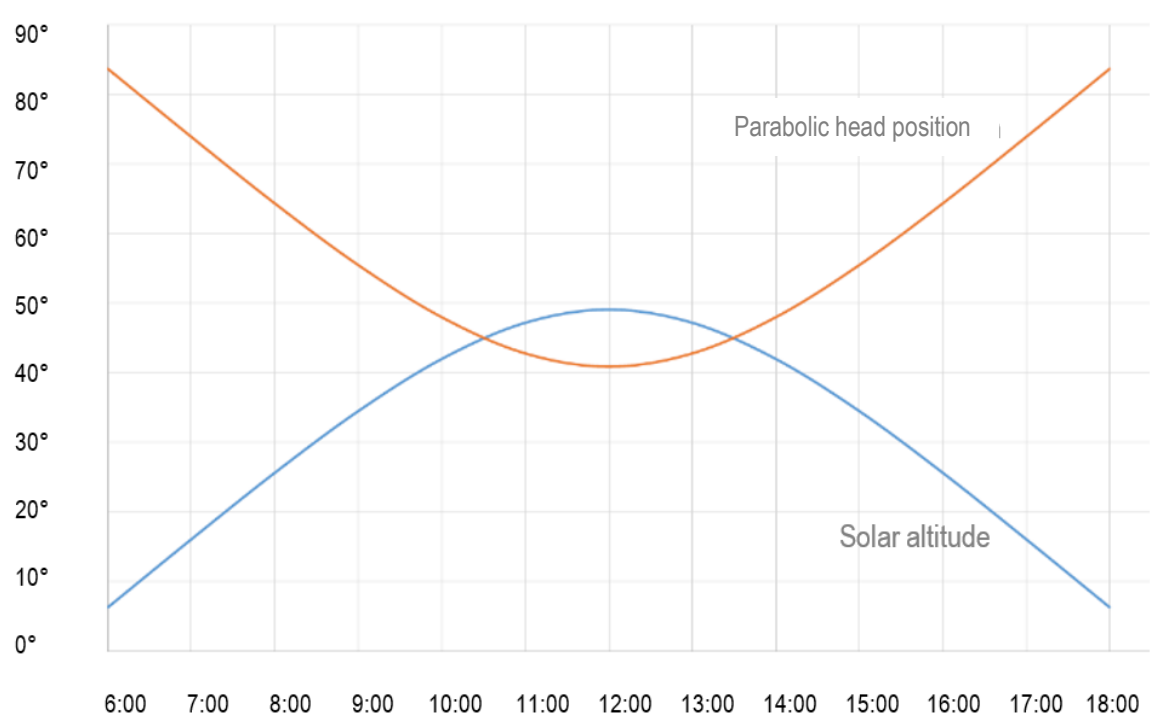

Figure 11: Dependence of the parabolic head position and orientation on solar altitude

\section{Conclusion}

Two comparable light guides with different roof installations were investigated. The case study was focused on evaluation of the common light guide with the glass roof dome and the new prototype with the roof concentrator head. The measured daylight illuminance data show light efficiency differences between two tested light guide systems. It was proven that the roof installation with the glass dome (LP2) is more efficient than the prototype with the light concentrator head (LP1). The concentrator head of the LP1 creates obstruction for daylight penetration in case of its static horizontal position. Daylight illuminance levels in the part of the test chamber illuminated by the LP1 are reduced about 37 percentage compared to that achieved the chamber illuminated by the LP2 system. The evaluation was done for conditions representing the region with temperate climatic with dominance of overcast and partly cloudy skies. Daylight simulations using software Holigilm give overview of daylight illuminance for tested light guides and comparison of measurements. Simulation outputs are in conformity with the measured data. The simulations also confirm that in this case the light guide with the concentrator head LP1 is less efficient system because gives lower illuminance level on the working plane indoors compared to the light guide LP2. The light guide prototype with the concentrator head LP1 was tested within the frame of the dissertation research. The further investigations of the light guide prototype is aimed at its installation in real buildings with different roof structures, slopes and orientations towards cardinal points. Some improvements of the light guide are recommended for its application in temperate climates as the system with movable concentrator heads completed with roof heliostats directing solar radiation inside of the light tube.

The installation of the concentrator head should be more efficient in sloped roofs oriented towards the south. The most efficient the light guide system LP1 would be in case when the light concentrator is equipped with a sun tracking system. This solution is more expensive compared to common light guides with glassed cupola. The sun-tracking light guide system is suitable for hot climates in installations exposed to intensive solar radiation. 


\section{Acknowledgements}

This article has been worked out under the project No. LO1408 "AdMaS UP - Advanced Materials, Structures and Technologies", supported by Ministry of Education of the Czech Republic, Youth and Sports under the „National Sustainability Programme I". Authors acknowledge company Lightway for the light guides for measurements and testing.

\section{References}

[1] Phillips, D. Daylighting: Natural Light in Architecture. Oxford: Architectural Press, Elsevier, 2004.

[2] Carter J., Developments in tubular daylight guidance systems, Building Research Information, 32 (2004), No. 3, 220-34.

[3] Rosemann, A., Kaase, H., Light pipe applications for daylighting systems. Solar Energy, 78 (2005), p. 772-780.

[4] Oakley G. et al., Daylight performance of light pipes. Solar Energy, 69 (2000), No. 2, 89-98.

[5] CIE 173. Tubular daylight guidance systems. Technical report, CIE, Vienna 2012.

[6] Carter, D.J., The measured and predicted performance of passive solar light pipe systems. Lighting Research and Technology, 34 (2002), No. 1, 39-51.

[7] Paroncini M., Calcagni, B., Corvaro, F., Monitoring of a light-pipe system, Solar Energy, 81 (2007), No. 9, 1180-1186.

[8] Li, D.H.W. Tsang, E.K.W., Tam, C.C.O., An analysis of light-pipe system via full-scale measurements. Applied Energy, 87 (2010), No. 3, 799-805.

[9] Marwaee A, Carter D., A field study of tubular daylight guidance installations, Lighting Research and Technology, 38 (2006), No. 3, 241-58.

[10] Su, Y, Khan, N. Riffat, S.B., Gareth, O., Comparative monitoring and data regression of various sized commercial light pipes. Energy and Buildings 50 (2012), 308-314.

[11] Mohelníková J. Evaluation of indoor illuminance from light guides. Light and Visual Environment, 32/1 (2008), No. 1, 20-26.

[12] Jenkins D., Muneer T., Modelling light-pipe performances - a natural daylighting solution. Building and Environment, 38 (2003), 965-972.

[13] Dobre, O., Achard, G., Optical simulation of lighting by hollow light pipes. Ninth Intern. IBPSA Conference, Building Simulation Montréal, 2005, 263-270.

[14] van Derlofske, J.F., Hough, T.A., Analytical model of flux propagation in light-pipe systems. Optical Engineering, 43, (2004), No. 7, 1503-1510.

[15] Samuhatananon, S., Chirarattananon, S., Chirarattananon, P., An Experimental and Analytical Study of Transmission of Daylight through Circular Light pipes, Leukos, 7 (2011), No. 4, 203 219.

[16] Kocifaj M., Darula, S., Kittler, R., HOLIGILM: Hollow Light Guide Interior Illumination Method - An Analytic Calculation Approach for Cylindrical Light-Tubes, Solar Energy, 82 (2008), 247-259.

[17] Dutton, S., Shao, L., Raytracing simulation for predicting light pipe transmittance. International Journal of Low-Carbon Technologies, 2/4 (2007), 339-358. 
[18] Diéguez, A.P., Light Pipes, Forward raytracing as a predictive tool and key design parameters. Thesis: EEBD-14/02, Lund University.

[19] Tejido, M.J.M. Conception and design of illumination light pipes, Thesis, Université de Neuchâtel, 2000.

[20] Schou, A., Investigation of light pipe simulation algorithms, Thesis, DTU, Kongens Lyngby 2012.

[21] Pacheco, D.A., Gentile, N., Von Wachenfelt, H., Dubois, M.-C., Daylight Utilization with Light Pipe in Farm Animal Production: A Simulation Approach, Journal of Daylighting 3/1 (2016), 111 .

[22] Ahmed S., Zain-Ahmed A., Rahman S. A., Sharif M.H., Predictive tools for evaluating daylighting performance of light pipes, International Journal of Low-Carbon Technologies, 1 (2006), 315-328.

[23] Malet-Damour, B., Boyer, H., Fakra, A.H., Bojic, M., Light Pipes Performance Prediction: inter model and experimental confrontation on vertical circular light-guides. Energy Procedia (2014), 57, 1977-1986.

[24] Luz, B., Monteiro, L.M., Alucci, M.P., Empirical and software verification of a simplified predictive model of luminous efficiency of light-pipes. Proceedings 30th International PLEA Conference 2014, CEPT University, Ahmedabad.

[25] Al-Marwaee M.B.A.O., Carter D.J., Tubular guidance systems for daylight: Achieved and predicted installation performances, Applied Energy 83/7, (2006),774-788.

[26] Freewan, A. Using tubular daylighting systems to improve illuminance level in double loaded corridors in educational buildings, Jordan Journal of Civil Engineering, 10 (2016), 184-196.

[27] Abd Kadir, A., Ismail, L. H., Kasim, N., Optimization of daylighting system by using light pipe system in a building. In Proceedings of the 2nd International Conference on Construction and Building Engineering, Padang, 2015, 1 - 9.

[28] Swift, P.D., Smith, G.B., Cylindrical mirror light pipes. Solar Energy Materials and Solar Cells 36 (1995), 159-168.

[29] Nair, M.G., Ramamurthy, K., Ganesan, A.R., Classification of indoor daylight enhancement systems, Lighting Research and Technology, 46, (2014), No. 3, 245-267.

[30] von Wachenfelt, H., Vakouli, V., Diéguez, A.P., Gentile , N., Dubois, M-C., Jeppsson, K-H., Lighting Energy Saving with Light Pipe in Farm Animal Production. Journal of Daylighting 2/2 (2015), 21-31.

[31] Bellia L., Fragliasso, F., Pedace, A. Evaluation of daylight availability for energy savings, Journal of Daylighting, 2 (2015) 12-20.

[32] Katunský, D.; Dolníková, E.; Dolník, B. Daytime Lighting Assessment in Textile Factories Using Connected Windows in Slovakia: A Case Study. Sustainability 2018, 10, 655.

[33] ISO 15469:2004(E)/CIE S 011/E:2003 Spatial distribution of daylight - CIE Standard General Sky. 